JITA: F: Management

\title{
O CONHECIMENTO NA PERSPECTIVA DA CONSTRUÇÃO SOCIAL: AS REDES SOCIAIS E A GESTÃO DO CONHECIMENTO EM AMBIENTES ORGANIZACIONAIS DE BIBLIOTECAS
}

KNOWLEDGE IN SOCIAL CONSTRUCTION PERSPECTIVE: SOCIAL NETWORKING AND KNOWLEDGE MANAGEMENT

IN ORGANIZATIONAL ENVIRONMENTS OF LIBRARIES

CONOCIMIENTO EN VISTA DE LA CONSTRUCCIÓN SOCIAL: REDES SOCIALES Y GESTIÓN DEL CONOCIMIENTO EN AMBIENTES ORGANIZACIONALES DE BIBLIOTECAS

\section{Liliane Juvência Azevedo Ferreira ${ }^{l}$ Lillian Maria Araújo de Rezende Alvares ${ }^{2}$ Dalton Lopes Martins ${ }^{3}$}

\begin{abstract}
RESUMO
A Gestão do Conhecimento constitui-se num complemento para a administração organizacional. Entre outras características, reconhece os fluxos informais de informação, cujo tratamento requer o uso de tecnologias, promovendo a criação, armazenamento e transferência do conhecimento. As Redes Sociais, neste contexto, representam os atores que criam, geram e disseminam esse conhecimento, reforçando a ideia de que o conhecimento organizacional se estabelece a partir da construção social. Este trabalho é um ensaio teórico cujo objetivo é apresentar algumas concepções que aproximam as temáticas Gestão do Conhecimento e Redes Sociais. Constitui-se numa pesquisa exploratória realizada por meio de revisão bibliográfica. Os resultados apontam que tais abordagens têm contribuído para a Ciência da Informação e podem ser aplicadas em ambientes organizacionais tais como bibliotecas. A metodologia de Análise de Redes Sociais pode ser uma importante aliada na promoção destes estudos.
\end{abstract}

PALAVRAS-CHAVE: Gestão do Conhecimento. Redes Sociais. Bibliotecas.

\begin{abstract}
Knowledge Management is a complement to the organizational administration. Among other features, it recognizes the informal information flows, whose treatment requires the use of technologies, promoting the creation, storage and transfer of knowledge. Social Networks, in this context, represent the actors that create, generate and disseminate this knowledge, reinforcing the idea that organizational knowledge is established from the social construction. This article is a theoretical essay whose goal is to introduce some concepts that approximate the themes Knowledge Management and Social Networking. It is an exploratory research conducted through a literature review. Results indicate that such approaches have contributed to the Science of Information and can be applied in organizational environments such as libraries. Social Network Analysis methodology can be an important ally in the promotion of these studies.
\end{abstract}

KEYWORDS: Knowledge Management. Social Networks. Libraries.

\section{RESUMEN}

La Gestión del Conocimiento es un suplemento en la administración organizacional. Entre otras características, reconoce los flujos informales de información, cuyo tratamiento requiere el uso de las tecnologías, la promoción

\footnotetext{
1 Mestranda em Ciência da Informação pelo Programa de Pós-Graduação em Ciência da Informação da Universidade de Brasília (PPGCInf/UNB). E-mail: 1juvencia@ hotmail.com

2 Professora da Faculdade de Ciência da Informação e do Programa de Pós-Graduação em Ciência da Informação da Universidade de Brasília (UnB). E-mail: lilllianalvares@unb.br

3 Professor no Departamento de Gestão da Informação da Faculdade de Informação e Comunicação da Universidade Federal de Goiás. E-mail: dmartins@gmail.com

Enviado em: 14/10/2015 - Aceito em: 09/12/2015
} 
de la creación, el almacenamiento y la transferencia de conocimiento. Las Redes Sociales en este contexto son los actores que crean, generan y transfieren este conocimiento, lo que refuerza la idea de que el conocimiento de la organización ocurre desde la construcción social. Esta obra es un ensayo teórico cuyo objetivo es presentar algunos conceptos que traen el tema de Gestión del Conocimiento y Redes Sociales. Está en una investigación exploratoria, a través de revisión de la literatura. Los resultados muestran que estos enfoques han contribuido a la Ciencia de la Información y se puede aplicar en ambientes organizacionales tales como bibliotecas. La metodología del Análisis de Redes Sociales puede ser un aliado importante en la promoción de estos estudios.

PALABRAS CLAVE: Gestión del Conocimiento. Redes Sociales. Bibliotecas.

\section{INTRODUÇÃO}

A sociedade atual tem utilizado o conhecimento como principal fator de produção. Após a Segunda Guerra Mundial, a civilização traçou um novo caminho pelo qual o conhecimento tomou o lugar do capital e da mão de obra. A tecnologia da informação começou a ser aperfeiçoada e o saber passou a ser o diferencial no gerenciamento de ferramentas, processos e produtos.

Nessa Sociedade do Conhecimento e Pós-Capitalista, conforme Drucker (1993), tornar o conhecimento produtivo em organizações é um papel gerencial e, para isso, são requisitos necessários: foco, concentração, oportunidades de mudanças e transformação do potencial em desempenho. As organizações, nesse sentido, têm buscado adequações tecnológicas e recursos humanos qualificados e especializados para sobreviverem às novidades dessa sociedade. E, assim, para que sucesso e vantagens ocorram, torna-se importante a Gestão do Conhecimento, na qual é dada atenção aos profissionais qualificados e dotados de competências e habilidades, os quais atribuem à organização o diferencial competitivo. Por Gestão do Conhecimento, entende-se a disseminação de conhecimento implícito nas práticas individuais e coletivas de uma organização, de modo que as experiências das pessoas, somadas ao conhecimento acumulado, são elementos estrategicamente importantes no desenvolvimento de uma organização.

Em Gestão do Conhecimento, as equipes compõem-se de redes de pessoas que detêm conhecimento institucional e especializado. Cada uma, em sua área de atuação, deverá interligar-se ao funcionamento estrutural como um todo, todas apoiadas nos objetivos institucionais. Esses profissionais precisam ter a preocupação de transmitir seus conhecimentos para uma geração futura, a qual, por sua vez, também caminhará nessa perspectiva de criação e transmissão de conhecimento. Para Drucker (1993), a Gestão do Conhecimento é a transformação da informação em motor para o desenvolvimento, existindo no trabalho o apreço ao conhecimento e à especialização profissional.

Assim, este estudo se propõe a apresentar algumas considerações teóricas acerca da Gestão do Conhecimento e sua relação com as teorias de Redes Sociais, bem como algumas abordagens sobre a Análise de Redes Sociais, as quais têm contribuído com a Ciência da Informação, podendo ser aplicadas em ambientes organizacionais tais como bibliotecas. 
Este artigo encontra-se dividido em sete seções. A primeira contém a introdução; a segunda apresenta a metodologia utilizada; as seções terceira, quarta, quinta e sexta trazem os resultados das abordagens teóricas recuperadas. Na sétima e última seção são feitas algumas considerações finais.

\section{METODOLOGIA}

Trata-se de uma pesquisa exploratória, qualitativa, de natureza básica, cujo método de pesquisa constitui-se numa revisão da literatura de base, de abrangência temática e específica, com abordagem bibliográfica, com a finalidade de fornecer um panorama geral ou um relatório do estado da arte do tema em questão por meio de um apanhado de documentos selecionados e estudados (NORONHA; FERREIRA, 2003). Foi realizada a partir da fundamentação teórica de uma pesquisa de mestrado em Ciência da Informação, em andamento, cujo tema é a Gestão do Conhecimento e a Análise de Redes Sociais, que será aplicada em uma biblioteca universitária do serviço público federal.

O levantamento de documentos foi realizado entre março de 2014 e junho de 2015, período em que se fez uma consulta em livros de acervos particulares e das bibliotecas da Universidade de Brasília (UnB) e Universidade Federal de Goiás (UFG), bem como em periódicos recuperados no Portal de Periódicos da CAPES e periódicos eletrônicos de acesso aberto, dentre outros textos complementares disponibilizados na disciplina Pesquisa Orientada do Programa de Pós-Graduação em Ciência da Informação da Universidade de Brasília. A seleção das fontes foi realizada utilizando-se as terminologias e/ou palavraschave: Gestão do Conhecimento, Redes Sociais e Análise de Redes Sociais.

\section{CONHECIMENTO NA PERSPECTIVA DA CONSTRUÇÃO SOCIAL}

Cada indivíduo tem uma perspectiva de mundo diferente, com projetos diferentes que, mesmo entrando em conflito com as individualidades, vive um mundo em comum por meio da correspondência de significados, concepções e interação social. Berger e Luckmann (2004) afirmam que, na vida cotidiana, a realidade se apresenta a partir de um mundo subjetivo caracterizado pela interação e comunicação entre os homens.

Toda atividade do homem pode se tornar um hábito, uma espécie de padrão que se estabelece na orientação para as atividades futuras. Os hábitos, quando compartilhados, formam ações rotineiras dos diversos atores de um contexto. Configuram-se em tipificações que levam à institucionalização, de modo que cada indivíduo é capaz de predizer as ações dos outros. A instituição, nesse sentido, refere-se à ordem social de uma determinada coletividade e seu conceito vai além do entendimento de espaço fisicamente estabelecido. É percebida como sistema de controle e orientação, norteada de regras para o funcionamento da sociedade. E, ainda, ramificada em organizações de segmentos específicos, quais sejam, religiosos, educacionais, econômicos, científicos etc. 
O conhecimento dos membros de uma determinada sociedade promove a integração de uma ordem institucional; é, consequentemente, a soma de tudo aquilo que todos sabem dentro de um complexo social formalizado num conjunto de princípios, valores, crenças e mitos que, reunidos, fornecem subsídios na formulação de regras e de definição de papéis institucionais adequados. "[...] um mundo social estará em processo de construção, contendo nele as raízes de uma ordem institucional em expansão" (BERGER; LUCKMANN, 2004, p. 83).

Logo, esse complexo corpo formado pelos saberes pode ser perfeitamente transmitido às gerações futuras. Essas experiências compartilhadas podem ser transmitidas por meio de sistemas comunicacionais que facilitam a transformação do objeto de conhecimento de um indivíduo no conhecimento coletivo aproveitável, tendo a linguagem como canal de disseminação. Nonaka e Takeuchi (1997) corroboram esse argumento quando afirmam que uma organização não pode criar conhecimento por si só; ela depende da iniciativa e interação dos indivíduos num grupo.

Num contexto socialmente caracterizado pelas relações institucionalizadas, os indivíduos apresentam, cada qual, um papel, que juntos são absorvidos pela instituição, como as habilidades e experiências particulares. Representam a intermediação do conhecimento, em que seu detentor - o indivíduo - envolve-se socialmente e compartilha seu domínio e apreende os domínios dos outros, fazendo funcionar o sistema social institucionalizado.

Em resumo, o conhecimento pode ser promovido por meio do encontro de indivíduos na sociedade, no atendimento de conveniências institucionalizadas, constituindo e orientando a realidade.

\section{GESTÃO DO CONHECIMENTO}

Com a frequente consideração da informação como recurso estratégico, as organizações começaram a valorizar questões como inovação, talento dos funcionários, tecnologias, relações com clientes e usuários. No entanto, a informação por si só não consegue auxiliar nas novas práticas e novas ideias (insights) (TARAPANOFF, 2006). Assim, em meados da década de 1990, o termo "capital intelectual" como a soma do conhecimento dos membros de uma empresa já se apresentava de forma promissora. Consequentemente, as concepções sobre a gestão desse capital, a Gestão do Conhecimento, passaram a ser um modelo bastante reconhecido.

A Gestão do Conhecimento é entendida como o gerenciamento fundamentado no uso do capital intelectual de uma organização, na criação, transferência e armazenamento de conhecimento (SILVA FILHO; SILVA, 2005). Suas iniciativas devem considerar as características do ambiente no qual são implementadas, como, por exemplo, a natureza do conhecimento, a cultura na qual os indivíduos fazem parte e seus comportamentos em relação à informação e ao conhecimento, considerando, ainda, as particularidades dos processos de 
comunicação próprios do ambiente (LEITE; COSTA, 2007). Também conhecida como Knowledge Management (KM), possui vários estudos e pesquisas científicas e é tema de vários eventos, o que mostra sua evolução teórica nos últimos anos. Facilita benefícios e rendimentos em uma organização, possibilitando a capacidade de ter acesso ao know-how dos membros (STEWART, 2002).

Valentim (2002) define a Gestão do Conhecimento como a importância dada ao capital intelectual de uma instituição, mapeando e reconhecendo os fluxos informais de informação, cujo tratamento requer o uso de tecnologias, promovendo a criação, armazenamento e transferência do conhecimento organizacional.

Terra (2001, p. 215) complementa a definição ao afirmar que a Gestão do Conhecimento pode ser entendida como a adoção de práticas gerenciais compatíveis e coordenadas de esforços nos níveis organizacional, individual, estratégico e operacional, com normas formais e informais; é caracterizada em sete dimensões: (1) definição dos campos de conhecimento pela alta administração; (2) estabelecimento de uma cultura organizacional que considera: inovação, experimentação e aprendizado contínuo; (3) estruturas organizacionais caracterizadas em equipes multidisciplinares; (4) práticas e políticas de administração de recursos humanos relacionadas às considerações de ambientes externos, bem como a geração, disseminação e armazenamento de conhecimento. Quadro de pessoal composto de pessoas com habilidades e competências para a empresa e destaque em planos de carreira e treinamentos e remuneração de acordo com as competências e responsabilidades; (5) estrutura informatizada com ênfase nas tecnologias de comunicação e nos sistemas de informação com indivíduos preparados para uso e manutenção; (6) esforços de análise de resultados do capital intelectual; (7) estreitamento de relações com o mercado externo e clientes/usuários.

Contudo, vários autores discorrem sobre Gestão do Conhecimento partindo de várias premissas. Alguns seguem o viés da Administração; outros, da Ciência da Informação, áreas mais atuantes nesses estudos. O fato é que as raízes dessas abordagens encontram-se nas concepções de importantes estudiosos precursores, cada qual com uma explicação.

Alvares, Baptista e Araújo Júnior (2010) elencam nove categorias conceituais nas quais descrevem a Gestão do Conhecimento. São elas: 


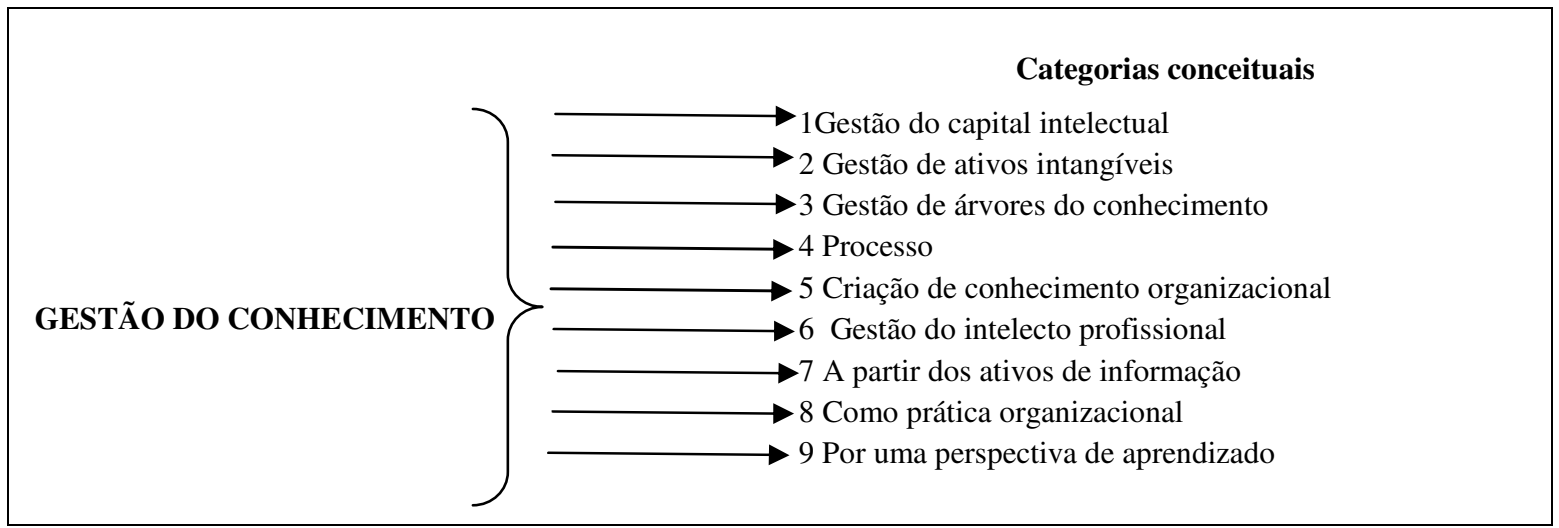

FIGURA 1 - Abrangência conceitual de Gestão do Conhecimento Fonte: adaptado de Alvares, Baptista e Araújo Júnior (2010).

Com o propósito de conhecer e compreender algumas dessas perspectivas conceituais sobre Gestão do Conhecimento, foram buscados na literatura alguns nomes relevantes, entre os quais se encontram as teorias de: Ikujiro Nonaka e Hirotaka Takeuchi, Pierre Lévy e Michel Authier, James Brian Quinn, Philip Anderson e Sydney Finkelstein, Thomas A. Stewart, Thomas H. Davenport e Laurence Prusak e Chun Wei Choo. Tais autores reforçam a concepção da construção social em seus modelos de Gestão do Conhecimento. Procurou-se ordená-los dentro de uma perspectiva cronológica, considerando a evolução dos estudos dessa temática a partir dos anos 90 (século XX).

\subsection{Ikujiro Nonaka e Hirotaka Takeuchi: o Conhecimento Organizacional}

As considerações de Nonaka e Takeuchi (1997) acerca da Gestão do Conhecimento estão ligadas às concepções da criação do conhecimento organizacional. Esses autores se baseiam no sucesso das empresas japonesas nas décadas de 1980 e 1990 para justificar a importância desse conhecimento na dinâmica das organizações.

Essas empresas enfrentaram situações de incertezas em relação à liderança e mesmo assim conseguiram garantir o sucesso por meio da capacidade de especialização na criação do conhecimento organizacional. Esse novo conhecimento ocorria, portanto, a partir de especulações e estudos de seus especialistas que, em seguida, o difundiam e o incorporavam em produtos e serviços, com um modelo de inovação contínua.

Com base nesses dados, o ponto de partida para a Gestão do Conhecimento reside na preocupação da organização em criar mecanismos de transferência dos saberes, inovando constantemente e desenvolvendo novas tecnologias e produtos para, assim, proporcionar vantagem competitiva. E essa dinâmica de saberes constitui a conversão de conhecimento tácito em conhecimento explícito, modalidades de conhecimento definidas por Nonaka e 
Takeuchi que foram inspiradas nas concepções do estudioso húngaro Michel Polanyi ${ }^{4}$, na década de 1960.

Por conhecimento tácito entende-se o conhecimento que as pessoas possuem, mas que não se encontra registrado ou documentado em nenhum lugar; trata-se de um saber subjetivo, meramente pessoal, o qual apresenta desafios em seu compartilhamento e transferência. É incorporado pelo indivíduo de forma técnica (aptidões, talentos e habilidades) e cognitiva (percepções de mundo, valores, emoções, subjetividade). Já o conhecimento explícito é aquele que está registrado e disponível para as pessoas, podendo ser transferido facilmente por meio de codificação-num sistema simbólico acessível.

A conversão do conhecimento é justamente a dinâmica que traduz a criação do conhecimento organizacional e esse processo é representado em quatro modos, conforme apresentado no Quadro 1:

\section{Socialização - (conhecimento compartilhado): Conhecimento Tácito em Conhecimento Tácito}

Conhecimento adquirido sem a necessidade de linguagem, mas por meio da observação, da prática, da experiência. Exemplos: equipes num projeto em constantes reuniões, diálogos, compartilhamento de experiência em local de trabalho com detentores de conhecimento e até mesmo interação com clientes.

Externalização - (conhecimento
conceitual): Conhecimento Tácito em
Conhecimento Explícito

Combinação - (conhecimento sistêmico): Conhecimento Explícito em Conhecimento Explícito

\begin{tabular}{ll}
$\begin{array}{l}\text { Internalização } \\
\text { operacional): Conhecimento Explícito } \\
\text { em Conhecimento Tácito }\end{array}$ & $\begin{array}{l}\text { Absorção do conhecimento explícito no tácito. Pode ocorrer a } \\
\text { partir da documentação de experiências do conhecimento } \\
\text { explícito pelo próprio indivíduo que ao longo do tempo } \\
\text { incorpora essas experiências. }\end{array}$ \\
\hline
\end{tabular}

QUADRO 1 - Modos de Conversão do Conhecimento

Fonte: elaborado pelos autores com base em Nonaka e Takeuchi (1997, p. 69).

A partir desses argumentos, evidencia-se que a Gestão do Conhecimento está relacionada, também, às práticas que visam à conversão de conhecimentos.

\footnotetext{
${ }^{4}$ Michael Polanyi (1891-1976) nasceu em Viena, mas viveu na Hungria. Formou-se em Medicina e serviu ao Exército austro-húngaro na I Guerra Mundial. Escolheu a cidadania austríaca durante a guerra. Na Alemanha, dedicou-se a trabalhos na área química e física no desenvolvimento de pesquisas como a absorção de gases, cristalografia e reação cinética. Fugiu da Alemanha nazista para a Inglaterra e se afastou da química e física, desenvolvendo estudos em economia, análise social e política, filosofia, teologia e estética (SCOTT; MOLESKI, 2005).
} 


\subsection{Pierre Lévy e Michel Authier: as árvores de conhecimento}

A identidade dos indivíduos não se limita ao nome, sexo, nacionalidade, mas engloba características particulares que surgem com o tempo, por meio do estudo contínuo e da experiência. E segundo Lévy e Authier (2000), num cenário onde se reúnem várias pessoas, cada qual com sua identidade, várias habilidades se juntam também. E é esse organismo que reproduz a realidade do conhecimento organizacional, podendo ser metaforicamente chamado de árvore do conhecimento, por meio do qual os indivíduos adquirem vantagens e reconhecimentos com base em seus saberes, habilidades e competências.

A árvore do conhecimento é um estudo dos processos que levam ao conhecimento, considerando que a vida constitui-se num processo no qual os indivíduos constroem seus saberes a partir da interação e das suas trajetórias (MATURANA; VARELA, 1995). As árvores de conhecimento de Lévy e Authier (2000) são caracterizadas como recursos que utilizam ferramentas como a informática, comunicação e imagens na exploração e identificação de competências de um ambiente específico, isto é, todo coletivo que participa do crescimento de uma mesma comunidade. As árvores não registram o saber em si, mas os sinais das pessoas que detêm o conhecimento.

A metáfora "árvore do conhecimento" remete ao texto bíblico, livro de Gênesis, capítulo 2, versículo 9 da Bíblia cristã que relata que na origem do mundo, no momento da criação das plantas, Deus criou recursos para que o homem pudesse plantar. Fez a chuva e deu ao homem a função de semear e lavrar (BÍBLIA, 1996). A árvore do bem e do mal do Jardim do Éden árvore da ciência ou do conhecimento - continha a orientação dada a Adão e Eva.

Diz o texto bíblico que, quando Adão e Eva comeram do fruto da árvore do conhecimento do bem e do mal, foram transformados em seres diferentes e nunca mais voltaram à antiga inocência. Antes, seu conhecimento do mundo se expressava em sua nudez. Viviam nessa nudez na inocência do mero saber. Depois, quando souberam que estavam nus, souberam que sabiam (MATURANA; VARELA, 1995, p. 261-262).

Além disso, a estrutura biológica de uma árvore, cujo crescimento acontece a partir do tronco e se desenvolve em galhos e folhas, conforme Levy e Authier (2000), explica também a metáfora. O tronco representa os conhecimentos primários que originam galhos e folhas, os quais são os conhecimentos aprimorados no ambiente. Algumas pessoas possuem mais galhos e mais folhas que outras. 


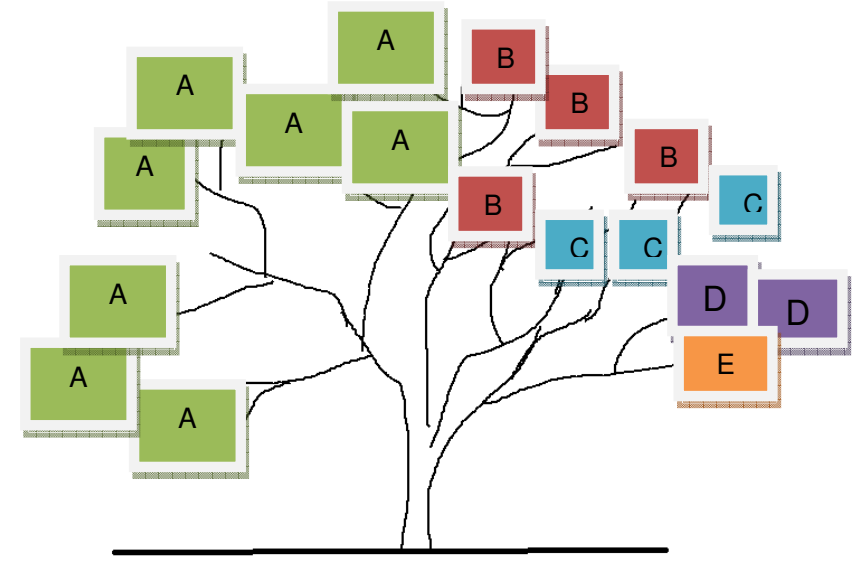

FIGURA 2 - Árvore de Conhecimento.

Fonte: elaborada pelos autores, 2015.

Logo que se insere numa comunidade, um indivíduo pode ser estimulado a receber uma representação de seus saberes - os brasões -, a qual pode evoluir para patentes: o reconhecimento de saberes. Na figura 2, os quadradinhos são as folhas, e as letras contidas neles representam as pessoas, indivíduos A, B, C, D e E. Observa-se que o indivíduo A possui mais experiências e competências que os demais.

Para Lévy e Authier (2000), as concepções de árvores do conhecimentos podem, ainda, extrapolar os limites da organização interna. São formadas com base na democracia, desenvolvendo um ambiente de aprendizado com o envolvimento de todos os membros. Seus principais efeitos agem sobre o indivíduo, o qual é estimulado a desenvolver seu conhecimento e construir sua identidade cognitiva, e sobre as organizações, as quais mobilizam competências e conquistam um posicionamento estratégico. Influenciam, também, os educadores e formadores, uma vez que atuam na avaliação e formação de novos atores. E, ainda, fazem associação à cidadania, uma vez que esses indivíduos podem identificar-se em comunidades de saber e suas diferenças tornam-se fontes de enriquecimento, inclusão e prosperidade.

\subsection{James Brian Quinn, Philip Anderson e Sydney Finkelstein: a Gestão do Intelecto Profissional}

Além das expressões "Gestão do Capital Intelectual" e "Gestão do Conhecimento", Quinn, Anderson e Finkelstein (2000) propõem um novo termo que também representa o cuidado e o reconhecimento dos saberes dentro de uma organização: "Intelecto Profissional”. Entretanto, com algumas características, sobretudo, bem peculiares sobre cada nível dos detentores de conhecimento, o que o diferencia das demais definições. $O$ intelecto profissional de uma organização se define em quatro níveis de operação, seguindo uma ordem crescente de complexidade, conforme pode ser observado no Quadro 2.

As organizações, para tanto, precisam focar nas questões mais qualitativas, criativas e consistentes, mesmo que em longo prazo. E para que esse investimento ocorra, algumas práticas podem ser bem-sucedidas, como: buscar melhores currículos, pessoas mais 
qualificadas, investir num desenvolvimento intensivo antecipado, aumentar os desafios profissionais, avaliar os profissionais e filtrar talentos.

\begin{tabular}{lll}
\hline \multicolumn{1}{c}{ Nível } & \multicolumn{1}{c}{ Característica } \\
\hline Nível 1 - Conhecimento Cognitivo & $\begin{array}{l}\text { Nível mais simples em que os profissionais adquirem os } \\
\text { conhecimentos básicos por meio de treinamentos. } \\
\text { Conhecimento obtido por meio de estudos, leituras e que se traduzem } \\
\text { na aplicação de problemas. }\end{array}$ \\
$\begin{array}{l}\text { Nível 2 - Habilidades Avançadas } 3-\text { Compreensão de } \\
\text { Sistemas }\end{array}$ & $\begin{array}{l}\text { Conhecimento que ultrapassa os limites das atividades rotineiras. Os } \\
\text { profissionais são capazes de planejar cenários e resolver problemas } \\
\text { mais complexos. }\end{array}$ \\
$\begin{array}{l}\text { Nível } \\
\text { Automotivada }\end{array}$ & $\begin{array}{l}\text { É o mais alto dos níveis, referindo-se à vontade e adaptabilidade rumo } \\
\text { ao sucesso, contando com grupos mais criativos. }\end{array}$ \\
\hline $\begin{array}{l}\text { QUADRO 2 - Níveis de operação do intelecto profissional numa organização } \\
\text { Fonte: elaborado pelos autores com base em Quinn, Anderson e Finkelstein (2000). }\end{array}$
\end{tabular}

Mesmo assim, alguns desafios precisam ser superados no intuito de acompanhar o contexto que vivem essas organizações e, assim, agilizar as atuações dos profissionais. É o que os autores chamam de "Alavancagem do Intelecto Profissional", como a implantação de algumas ferramentas e adequações, quais sejam, implantação de softwares e outras tecnologias de informação, incentivo no compartilhamento de informações, reorganização hierárquica e criação das "Spiders' Webs", ou "teias de aranhas", que se configuram em teias temporárias na união de pessoas em atuação em situações específicas.

\subsection{Thomas A. Stewart: gestão do Capital Intelectual e os ativos intangíveis}

O conhecimento tornou o trabalho físico mais inteligente e aqueles profissionais que se intensificavam fisicamente foram substituídos, em alguns casos, por profissionais mais atuantes intelectualmente. Estes são mais determinados em suas análises e contam com ferramentas de comunicação mais rápidas. As empresas tendem a procurar mecanismos de desvinculação dos ativos tangíveis, ou maximizar seu retorno sobre eles, aumentando seu capital intelectual, que se refere aos talentos e às habilidades. "Capital intelectual é o conhecimento que transforma as matérias-primas e as torna mais valiosas" (STEWART, 2002, p. 40).

Stewart (2002) elenca quatro passos no desenvolvimento de estratégias organizacionais voltadas ao capital intelectual, conforme demonstrado no Quadro 3. 


\section{Passo $\quad$ Definição}

\begin{tabular}{|c|c|}
\hline $\begin{array}{l}\text { 1- Identificar e avaliar o papel do conhecimento } \\
\text { em seu trabalho }\end{array}$ & $\begin{array}{l}\text { Como e a intensidade do connecimento organizacional, } \\
\text { quem faz o quê, para quem e qual o valor. }\end{array}$ \\
\hline $\begin{array}{l}2 \text { - Associar receitas aos ativos do conhecimento } \\
\text { que as produzem }\end{array}$ & $\begin{array}{l}\text { Qual a expertise, quais as capacidades, as marcas, as } \\
\text { propriedades intelectuais, os processos lucrativos. }\end{array}$ \\
\hline $\begin{array}{l}3 \text { - Desenvolver uma estratégia para reforçar e } \\
\text { explorar ativos intelectuais }\end{array}$ & $\begin{array}{l}\text { Qual o modelo de lucros, qual a estratégia para } \\
\text { aumentar o conhecimento no negócio. }\end{array}$ \\
\hline $\begin{array}{l}4 \text { - Melhorar a eficiência do trabalho do } \\
\text { conhecimento } \\
\text { conhecimento }\end{array}$ & $\begin{array}{l}\text { Criação de mecanismos para aumentar a produtividade } \\
\text { dos trabalhadores do conhecimento. }\end{array}$ \\
\hline
\end{tabular}

QUADRO 3 - Processo de quatro passos para o gerenciamento do Capital Intelectual

Fonte: elaborado pelos autores com base em Stewart (2002, p. 124).

É possível afirmar a partir dessas estratégias que um modelo de Gestão do Conhecimento eficiente compreende, no entanto, a implementação de meios para descobrir os conhecimentos existentes e, em seguida, organizá-los em atividades que requeiram inteligência, dinâmica e agilidade, tendo em vista que os ativos de conhecimento são fundamentais. Os executivos que exercem suas funções em razão dessa prática são o executivo do conhecimento, o executivo da informação e o executivo do aprendizado. Eles podem atuar utilizando-se ferramentas como banco de dados, relatórios de medidas do capital intelectual, bibliotecas corporativas, intranets, groupwares, programas de treinamento, projetos de mudanças culturais, estímulos à colaboração, criação de organizações virtuais etc.

Todavia, se essas atividades já estiverem instaladas, mas não forem utilizadas, ou caso sejam subutilizadas, não fazem o menor sentido e não há trabalho voltado para o conhecimento. Em razão disso, para que a Gestão do Conhecimento tenha menos falhas possíveis, torna-se conveniente questionar que conhecimento será gerenciado e qual a sua finalidade. Stewart (2002) sugere quatro questões importantes que merecem atenção: (1) Qual é o grupo de trabalho? (2) O que o grupo precisa saber? (3) Você padroniza ou personaliza? (4) Qual a natureza do conhecimento? A partir dessas reflexões, o grupo que lida com a Gestão do Conhecimento é capaz de entender melhor qual a finalidade da implantação e prosseguimento dessas atividades.

\subsection{Thomas H. Davenport e Laurence Prusak: processos motivacionais e o mercado de conhecimento}

A Gestão do Conhecimento numa instituição funciona a partir da valorização e motivação dos seus atores. É importante tornar o conhecimento organizacional reconhecido entre seus membros de uma forma recíproca, pois ele só se torna valioso a partir de sua acessibilidade.

A organização deve ter uma visão ampla na compreensão do mercado do conhecimento e, para tanto, torna-se necessário entender as lógicas sociais, econômicas e políticas, em que o intercâmbio de conhecimento destaca-se como uma atividade importante. De nada adianta manter o conhecimento individual enraizado se a intenção da empresa é o crescimento a partir da Gestão do Conhecimento. O sistema de valores nesse mercado envolve a 
reciprocidade, a reputação e o altruísmo. E para que esses três fatores funcionem positivamente, é preciso ter confiança mútua e alguns indicadores de acesso ao conhecimento, como os indicadores formais (títulos, posições dentro da empresa e a escolaridade) e os indicadores informais, que são aqueles configurados pelos relacionamentos.

As pessoas procuram, neste contexto, quem sabe sobre um assunto por meio dos diálogos casuais, trocas de informações cotidianas e, ainda, pelos grupos mais diretos, como seções e departamentos. Mesmo assim, esse mercado de conhecimento não é totalmente eficiente, pois algumas dificuldades têm impedido as organizações de conseguirem recuperar informações e encontrar conhecimento. Dentre essas dificuldades estão as informações limitadas, o conhecimento concentrado e a sobrecarga de trabalho. E é justamente diante dessas dificuldades, que interferem na qualidade da gestão, que Davenport e Prusak (2003) apresentam seu modelo de Gestão do Conhecimento, conforme apresentado na Figura3.



FIGURA 3 - Fluxograma do Conhecimento Organizacional, de Davenport e Prusak. Fonte: elaborada pelos autores, com base em Danveport e Prusak (2003).

Os trabalhadores da Gestão do Conhecimento deverão concentrar-se nessa atividade como tarefa prioritária, e, para tanto, as novas tecnologias da informação apresentam-se como um sistema de valiosa função, tornando ágil o processo de distribuição e armazenamento de conhecimento. Os esforços nesse sentido envolvem sistemas especializados, raciocínios fundamentados em casos (resolver problemas novos com base em experiências anteriores) e em redes neurais (modelos computacionais capazes de reconhecer padrões), a web, a videoconferência, os repositórios (banco de dados), entre outros. Todavia, deve-se considerar que essas tecnologias não criam o conhecimento, tampouco promovem a geração e o compartilhamento. São ferramentas intermediárias e, embora nem todas requeiram usuários altamente capacitados, os trabalhadores de Gestão de Conhecimento precisam ter um entendimento básico para que os usos sejam bem-sucedidos.

\subsection{Chun Wei Choo: Gestão do Conhecimento como processo e as três arenas}

Uma estrutura organizacional formada de pessoas que buscam dar significado às informações, gerar conhecimento e, em seguida, tomar decisões, proporciona um modelo organizacional inovador. Essa é a concepção de Choo (2006) em relação à importância do 
conhecimento nas organizações. Esse autor afirma que o conhecimento é disseminado de várias maneiras. E, em vista disso, o conhecimento organizacional é gerado a partir da integração de processos, a qual é composta pelo que o autor denomina de "arenas", relacionadas ao uso da informação - criação de significado, construção de conhecimento e tomada de decisões - num ciclo contínuo de interpretação, aprendizagem e ação. Esse é o modelo de gestão do conhecimento na visão desse autor, de acordo com a Figura 4.

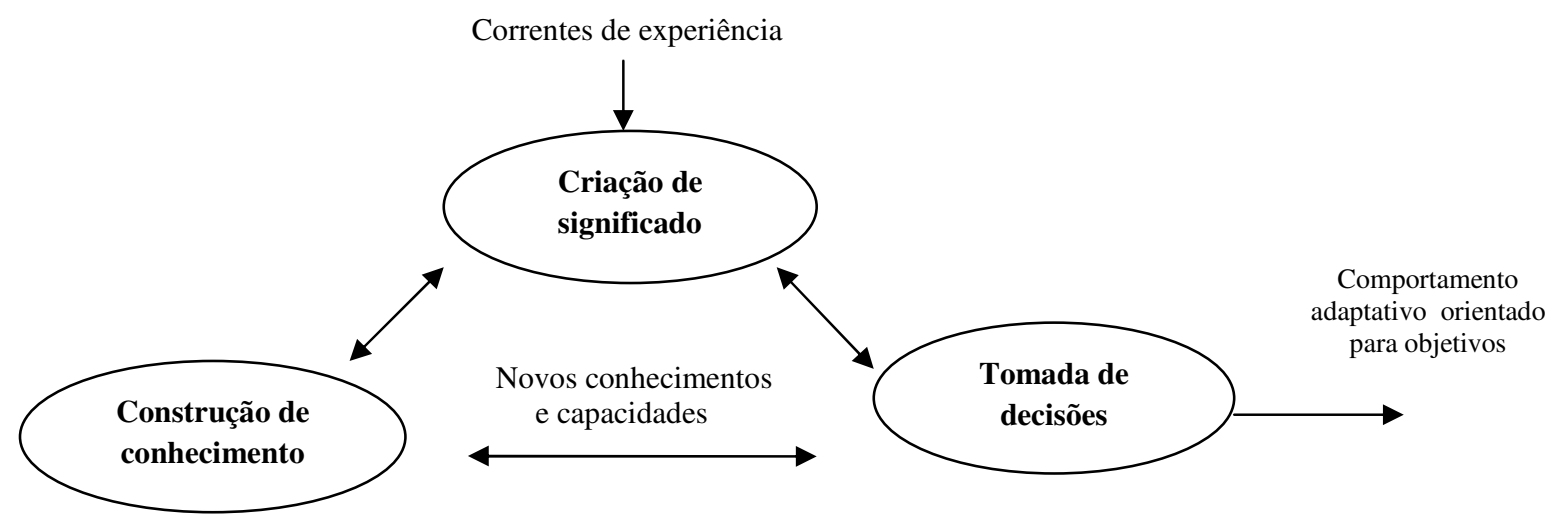

FIGURA 4 - O Ciclo de Conhecimento Fonte: (CHOO, 2006, p. 50).

A Criação de Significado é composta pelas interpretações de mensagens e discussões dos membros de uma equipe na construção de consensos acerca dos objetivos institucionais, ambientes externos e internos. A Construção de Conhecimento, assim como a compreendem Nonaka e Takeuchi (1997), refere-se aos quatro níveis: socialização, exteriorização, combinação e internalização. A Tomada de decisões diz respeito à escolha de estratégias indispensáveis, fazendo da organização um sistema racional que prevê problemas futuros, cria mecanismos na construção de cenários e busca alternativas.

Levando-se em consideração esses três modelos de uso da informação, é possível afirmar que são processos interdependentes que formam o ciclo do conhecimento. Em suma, Choo (2006) corrobora as concepções que definem a Gestão do Conhecimento, dentre as quais as de Nonaka e Takeuchi (1997), em que a criação do conhecimento organizacional eleva o nível de especialização de seus membros. O uso das informações é realizado com o intuito de gerar conhecimento, facilitado pela comunicação e surtindo efeito de inovação estratégica.

\section{PERSPECTIVAS DE REDES SOCIAIS NO CONTEXTO DA GESTÃO DO CONHECIMENTO EM ORGANIZAÇÕES}

As concepções de Redes Sociais não se resumem às redes pelas quais as mídias sociais criam e representam, conforme vem sendo divulgado atualmente, e sim, às relações que permitem aprendizagem, convivência e compartilhamento de ideias. Caracterizam-se como um conjunto de indivíduos que unem recursos e ideias de interesses comuns, constituindo-se em espaços onde a interação cotidiana entre as pessoas permite a construção coletiva, a 
colaboração, o compartilhamento de ideias de interesses recíprocos do grupo social composto (MARTELETO, 2001).

Marteleto (2010, p. 30-31) identifica dois planos para as Redes Sociais: as Redes Sociais Primárias - interações informais do dia a dia que acontecem em casa, com a família, com vizinhos e com amigos, e as Redes Sociais Secundárias - interações e discussões formais com grupos organizacionais ou institucionais a partir da troca de experiências.

Nas redes secundárias, é possível identificar o conhecimento organizacional, gerado a partir do processo de integração organizacional, onde as pessoas são interligadas por uma rede estruturada com propósitos comuns, formando as "Redes de Conhecimento".

As Redes de Conhecimento são elos sistemáticos que configuram as relações de conhecimento dentro de uma organização ou instituição. As informações precisam ser interpretadas por atores que compartilham seus conhecimentos individuais, gerando benefícios em comum (JOHNSON, 2011; FLEURY, 2003) ${ }^{5}$. Sob a égide desses argumentos, observa-se que o conhecimento organizacional está nos atores institucionais que o detêm. E essa lógica pode ser compreendida como uma "Rede de Conhecimento Organizacional" composta de pessoas estrategicamente envolvidas em ambientes organizacionais. Nas redes de conhecimento organizacionais, tudo ocorre de forma bastante subjetiva, dependendo da cooperação, da bagagem intelectual, cultural e organizacional dos atores nelas envolvidos. Apresentam-se como ambientes de aquisição de conhecimentos de um campo ou tema e, na perspectiva organizacional, fortalecem o relacionamento recíproco, compreendendo o desenvolvimento de novas ideias e processos (TOMAÉL, 2008).

Kleindorfer, Wind e Gunther (2012) observam que o conhecimento organizacional pode perder o sentido se separado do contexto social ao qual faz parte; ele pertence às redes sociais que lhe dão forma. À organização compete, então, a estruturação das equipes, no intuito de criar mecanismos para um entendimento comum, utilizando e valorizando seu capital intelectual como recurso administrativo.

\footnotetext{
${ }^{5}$ Ademais, essa concepção vinculada à organização, as redes de conhecimento possuem outras compreensões. São, no geral, redes com o objetivo de criar e disseminar conhecimento a favor do desenvolvimento. O que as diferenciam é a diversidade de prática, corporificando-se como equipes de projetos, grupos de pesquisa, comunidades profissionais e de prática, redes de consultoria, conhecimento de membros de escola, das academias, grupos de apoio etc. Podem, também, ser redes formadas por pessoas com o mesmo objetivo de promoção de seu conhecimento e de outrem (TEIXEIRA; SOUZA, 2012, p. 4). Nesta pesquisa, as redes de conhecimento em questão são aquelas estabelecidas em ambientes organizacionais, denominadas Redes de Conhecimento Organizacionais.
} 


\subsection{Análise de Redes Sociais (ARS)}

A partir do entendimento de que as Redes Sociais traduzem a compreensão do vínculo entre indivíduos e o compartilhamento recíproco de ideias, torna-se importante uma metodologia que possibilite entender as suas configurações e os processos relacionais.

A Análise de Redes Sociais (ARS) é uma metodologia interdisciplinar que surgiu a partir dos estudos sociométricos ${ }^{6}$. Faz mapeamentos das relações sociais de um contexto e sua investigação não se concentra no indivíduo, mas numa entidade constituída por um conjunto de indivíduos e suas ligações recíprocas. Os métodos devem se basear no entendimento prévio de conceitos fundamentais, como atores, grupos, relação, rede, entre outros (WASSERMAN; FAUST, 1994). Marteleto (2010, p.30) define o campo de ARS como referenciado por uma perspectiva estrutural, baseada em laços, interligando atores sociais, fundamentado em dados empíricos sistematizados e configurados por representações gráficas, em que seus estudos dependem de modelos matemáticos e computacionais.

Para tanto, a teoria dos grafos tornou-se importante aliada nessas análises. Ela se propõe a investigar as relações de um conjunto, facilitando as respostas de questões relevantes. A ilustração de uma rede social, representada por um grafo, mostra que um conjunto de pontos ou nós (vértices), que se juntam aos pares por linhas (arestas), significa conhecimento e ideias em comum, podendo ser uma rede social de uma escola, de uma empresa, de grupos de cientistas, de uma comunidade etc. Segundo Barabási (2002), a estrutura de grafos ou redes leva à compreensão do mundo, e as mudanças topológicas, sejam em nós ou em vínculos, podem gerar avaliações e permitir novas possibilidades.

A Figura 5 apresenta um modelo de grafo elaborado por meio de software específico ${ }^{7}$.

\footnotetext{
${ }^{6}$ A Sociometria surgiu na década de 1930, partindo da premissa de que a sociedade é uma estrutura composta de relacionamentos entre indivíduos. Trata-se de uma ferramenta analítica de pesquisa e controle de informação sobre os padrões de conexão formados pelas relações entre as pessoas. Ademais, pretendia ser uma técnica de mudança social, explicitando informações sobre como um grupo de pessoas se relacionava, estruturas hierárquicas e de poder (MARTINS, 2012, p.17).

${ }^{7}$ Este grafo é resultado de um piloto da pesquisa de mestrado em andamento sobre Gestão do Conhecimento e Análise de Redes Sociais. O teste constituiu em questionário que foi aplicado no Laboratório de Políticas Públicas Participativas da Faculdade de Informação e Comunicação da Universidade Federal de Goiás (Labicom/Fic/UFG). Este grafo corresponde à questão: "Você compreende os conhecimentos e competências de quais pessoas? Você não precisa ter os mesmos conhecimentos, mas pelo menos, compreender o que faz seus colegas, o que eles dominam." A expressão "ME" é um código para os atores (nós) que significa "membro", e o número ao lado corresponde ao grau de entrada (número de conexões recebidas).
} 


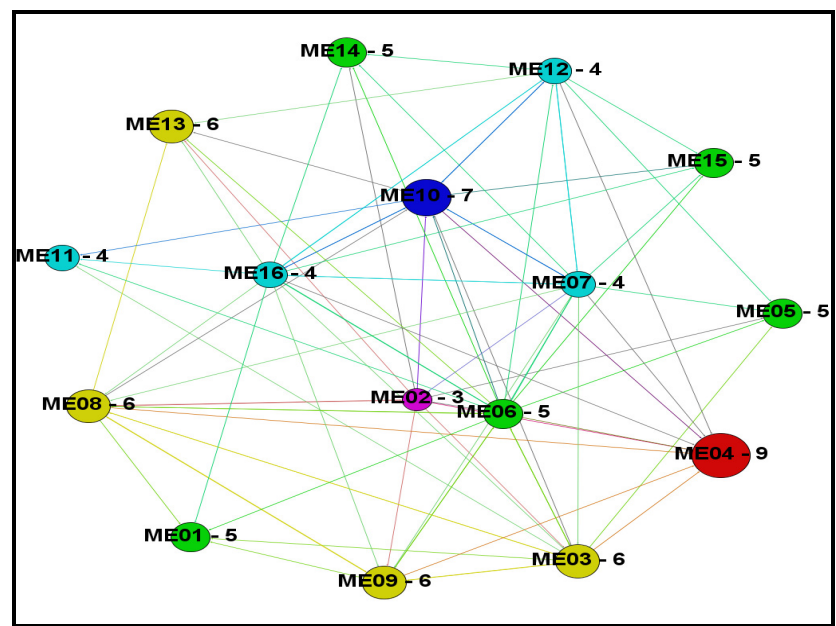

FIGURA 5 - Modelo de Grafo

Fonte: elaborada pelos autores, software Gephi 0.8.2, 2015.

A coleta dos dados para estudos de redes, conforme Wasserman e Faust (1994), ocorre por meio de técnicas comuns à pesquisa científica, como questionários, entrevistas, observações e banco de dados. O contexto para a análise de redes é amplo e diversificado, podendo ser as relações entre pessoas, redes de coautoria em trabalhos científicos, processos químicos celulares, conexões aéreas, entre outros (MARTINS, 2012).

Alguns recursos analíticos são comuns no auxílio das representações gráficas, dentre os quais, softwares geradores de grafos, como, por exemplo, os programas UCINET, Graph Viz, Gephi, entre outros. Essas ferramentas, quando combinadas com os dados coletados e transformados em métricas e representações gráficas, podem revelar as relações, as dinâmicas, os fluxos e a comunicação entre si, favorecendo as análises qualitativas. Dentre as métricas comuns, têm-se medidas dos atores (grau, proximidade, intermediação, centralidade, entre outras), medidas das relações (frequência, intensidade, direção etc.) e medidas gerais da rede (tamanho, abrangência, densidade etc.) (MOORE, 2002).

\subsection{ARS na Ciência da Informação}

Na Ciência da Informação, os estudos que utilizam a ARS têm contribuído com a área desde o final dos anos 90, como meio capaz de analisar dados sobre estudos da informação registrada, bem como redes de coautoria, por exemplo. Buscam também entender dados sobre a interação e a troca de informações entre indivíduos de um sistema ou grupo organizacional, enriquecendo as pesquisas sobre recuperação da informação, infometria, análise de citações, fluxos de informação nos movimentos sociais, colégio invisível, comunidades de prática, gestão do conhecimento, socialização da informação, novas tecnologias etc. (MATHEUS; SILVA, 2006). O Quadro 4 revela o detalhamento dos problemas da Ciência da Informação que podem ser respondidas pela ARS. 


\section{Problemas}

Acesso à Informação e tipos de usuários da informação

Difusão da inovação e de novas ideias

Acesso à informação como vantagem social

Acesso à informação e novos canais de informação, redes de computadores

Análise de coautoria, de citações e de cocitação, artigos científicos e colaboração científica Fluxos de informação dentro das organizações, Gestão do Conhecimento, tomada de decisão

QUADRO 4 - Problemas de Pesquisa Relevantes à Ciência da Informação no Contexto da Análise de

Redes Sociais

Fonte: adaptado de Matheus e Silva (2006).

Martins (2012) elenca 69 trabalhos (teses e dissertações) registrados na Biblioteca Digital Brasileira de Teses e Dissertações do Instituto Brasileiro de Informação em Ciência e Tecnologia (BDTD/IBICT), no ano de 2010, que desenvolveram pesquisa em redes sociais na Ciência da Informação. Esses dados confirmam, contudo, que ainda se trata de uma metodologia pouco usada na Ciência da Informação. Mesmo assim, tem sido importante para muitos estudos dessa grande área.

\section{OS AMBIENTES ORGANIZACIONAIS DE BIBLIOTECAS}

As bibliotecas possuem como propósito básico a criação de estrutura para que seus usuários de informação tenham acesso à produção científica necessária. Como ambientes organizacionais, possuem três funções básicas: (1) função gerencial: administração e organização; (2) função organizadora: seleção, aquisição, catalogação, classificação e indexação; (3) função divulgação: referência, empréstimo, orientação, reprografia, serviços de disseminação, extensão (ARAÚJO; OLIVEIRA, 2005, p. 38).

Em termos profissionais, lidar com a informação na contemporaneidade exige dos especialistas de bibliotecas competências e habilidades muitas vezes respaldadas por influências interdisciplinares no trato das questões que carecem de solução (BARBOSA, 1998). O aperfeiçoamento da equipe torna-se importante, visto que, nas bibliotecas, serão evidentes as melhorias de seus serviços com base nas novidades idealizadas a partir de estudos realizados pelos especialistas que estão à frente das atividades.

A biblioteca pode absorver algumas práticas de Gestão do Conhecimento em suas rotinas de trabalho, haja vista que os bibliotecários, a partir de suas habilidades de busca e recuperação de informação, possuem técnicas bem desenvolvidas para encontrar o que as pessoas precisam. Davenport e Prusak (2003) afirmam que, para além de suas responsabilidades técnicas, podem agir como intermediários de conhecimento dentro da sua rede de trabalho, são qualificados para a tarefa de criar contatos, guiando pessoa-pessoa, e intermedeiam a interação entre "compradores e vendedores" de conhecimento.

Enfatizar em equipes de bibliotecas a importância das práticas de Gestão do Conhecimento poderá auxiliar no entendimento de que a disseminação do conhecimento organizacional 
servirá como uma continuação rumo ao alcance dos objetivos e melhoria na realização das tarefas biblioteconômicas. Sua implantação sugere uma linha de propósitos que as redes de especialistas poderão seguir por várias gerações sabendo onde buscar e como usar as informações institucionais. Estudar as redes de profissionais de bibliotecas, assim como em qualquer ambiente organizacional, poderá auxiliar no entendimento da configuração dos vínculos relacionais favoráveis, como: cultura organizacional voltada ao conhecimento; uso de tecnologias da informação; preocupação com transferência e disseminação de conhecimento; gerenciamento de competências e definições de estratégias, entre outros.

\section{CONSIDERAÇÕES FINAIS}

Buscou-se, a partir do levantamento teórico realizado, apresentar a relação entre os conceitos Gestão do Conhecimento e Redes Sociais. Para a Ciência da Informação, estes temas apresentam elementos interessantes, tais como: tratamento de estruturas que lidam com tecnologia e organização da informação e consideração do conhecimento como peça importante para o sucesso organizacional. O estudo de Redes Sociais nesse contexto confirmará que a metodologia de ARS serve de apoio, tendo em vista que, conforme Le Coadic (2004), a Ciência da Informação é também uma ciência social que, aliada aos princípios técnicos aplicados, contribui fortemente na formação dos indivíduos por meio da compreensão social e cultural.

Entender como as organizações utilizam o conhecimento de suas equipes na execução de suas atividades é imprescindível, e no contexto das organizações atuais, como as bibliotecas, o conhecimento pode ser o insumo básico para o diferencial estratégico, consolidando-se, bem como a informação, um elemento de diferenciação para a competitividade organizacional.

Além dos objetivos educacionais e pedagógicos, a biblioteca precisa se preocupar, também, a respeito de como lidar com o conhecimento de seus especialistas, isto é, como administrar os saberes de sua equipe, pois se são os especialistas da organização (funcionários, técnicos) os executores, eles deverão, inclusive, saber alocar o conhecimento para uso produtivo. Sem os funcionários, sem os especialistas, sem as tecnologias e processos, esses objetivos tornam-se inatingíveis. A rede social desses ambientes, ilustrada por meio da ARS, poderá mostrar como esses relacionamentos funcionam na prática e proporcionar, por meio da interpretação, uma discussão sobre os ajustes necessários e as falhas que poderão ser melhoradas, sugerindo resultados que possam servir de referência, inclusive, para outras instituições.

Pretende-se, nas etapas futuras desta pesquisa em andamento, examinar o fluxo de conhecimento da equipe de um sistema de bibliotecas e observar a configuração dos relacionamentos no que se refere à Gestão do Conhecimento. Com o auxílio da ferramenta Gephi, serão gerados grafos que, a partir de suas métricas, layouts e filtros, possibilitarão a interpretação dos vínculos. 


\section{REFERÊNCIAS}

ALVARES, Lillian.; BAPTISTA, Sofia Galvão; ARAÚJO JÚNIOR, Rogério Henrique de. Gestão do Conhecimento: categorização conceitual. Em Questão, Porto Alegre, v.16, n.2, p.235-252. jul./dez. 2010. Disponível em:

<http://seer.ufrgs.br/index.php/EmQuestao/article/view/15124/10437>. Acesso em: 10 ago. 2014.

ARAÚJO, Eliany Alvarenga de; OLIVEIRA, Marlene de. A produção do conhecimento e a origem das bibliotecas. In: OLIVEIRA, Marlene de. Ciência da Informação e

Biblioteconomia: novos conteúdos e espaços de atuação. Belo Horizonte: Editora UFMG, 2005.

BARABÁSI, Albert-László. Linked [Conectado]: a nova ciência dos networks: como tudo está conectado a tudo e o que isso significa para os negócios, relações sociais e ciências. São Paulo: Leopardo Editora, 2002.

BARBOSA, Ricardo Rodrigues. Perspectivas profissionais e educacionais em Biblioteconomia e Ciência da Informação. Ciência da Informação, Brasília, v.27, n.1, p.5360, jan./abr. 1998. Disponível em: <http://www.scielo.br/pdf/ci/v27n1/07.pdf>. Acesso em: 23 mai. 2014.

BERGER, Peter L.; LUCMANN, Thomas. A construção social da realidade. Petrópolis: Vozes, 2004.

BÍBLIA. Português. Bíblia Sagrada.Tradução Centro Bíblico Católico. São Paulo: Editora Ave-Maria, 1996.

CHOO, Chun Wei. A organização do conhecimento: como as organizações usam a informação para criar significado, construir conhecimento e tomar decisões. São Paulo: SENAC, 2006.

DAVENPORT, Thomas H.; PRUSAK, Laurence. Conhecimento empresarial. Rio de Janeiro: Campus, 2003.

DRUCKER, Peter. Sociedade pós-capitalista. São Paulo: Pioneira, 1993.

FLEURY, André Leme. Redes de conhecimento: aplicações temáticas e regionais. In: ENEGEP, 23., 2003. Ouro Preto, MG. Anais... Ouro Preto, MG, 2003. Disponível em: $<$ http://ppgep.poli.usp.br/5179/Redes-de-Conhecimento-aplicacoes-tematicas-eregionais.html>. Acesso em: 10 mai. 2014.

JOHNSON, J. David. Gestão de redes de conhecimento. São Paulo: SENAC, 2011.

KLEINDORFER, Paul R.; WIND, Yoram; GUNTHER, Robert E. O desafio das redes: estratégia, lucro e risco em um mundo interligado. Porto Alegre: Bookman, 2012.

LE COADIC, Yves François. A ciência da informação. 2.ed. Brasília: Briquet de Lemos, 2004. 
LEITE, Fernando César Lima; COSTA, Sely Maria de Souza. Gestão do Conhecimento científico: proposta de um modelo conceitual com base em processos de comunicação científica. Ciência da Informação, Brasília, v.36,p.92-107, 2007.

LÉVY, Pierre; AUTHIER, Michel. As árvores de conhecimento. São Paulo: Escuta, 2000.

MARTELETO, Regina Maria. Análise de redes sociais - aplicação nos estudos de transferência da informação. Ciência da Informação, Brasília, v.30, n.1, p.71/81, jan./abr. 2001. Disponível em: < http://revista.ibict.br/ciinf/index.php/ciinf/article/view/226l>. Acesso em: 03 abr. 2015.

MARTELETO, Regina Maria. Redes Sociais, mediação e apropriação de informação: situando campos, objetos e conceitos na pesquisa em Ciência da Informação. Pesq. Bras. Ci. Inf., Brasília, v.3, n.1, p.27-46, jan./dez.2010. Disponível em: < http://inseer.ibict.br/ancib/index.php/tpbci/article/viewArticle/26>. Acesso em: 03 abr. 2015.

MARTINS, Dalton Lopes. Análise de redes sociais de colaboração científica no ambiente de uma federação de bibliotecas digitais. 2012. 236fl. Tese (Doutorado em Ciência da Informação da Universidade de São Paulo) - Programa de Pós-Graduação em Ciência da Informação da Universidade de São Paulo, São Paulo, 2012.

MATHEUS, Renato Fabiano; SILVA, Antônio Braz de Oliveira e. Análise de redes sociais como método para Ciência da Informação. Datagramazero: Revista da Ciência da Informação, Rio de Janeiro, v.7, n.2, abr. 2006. Disponível em: < http://www.dgz.org.br/abr06/Art_03.htm>. Acesso em: 03 abr.2015.

MATURANA, Humberto; VARELA, Francisco. A árvore do conhecimento: as bases biológicas do entendimento humano. São Paulo: Editorial Psy II, 1995.

MOORE, Dale. L. A social network analysis of the national materials competency at naval air systems command. 2002.181fl. Dissertação (Mestrado) Naval Postgraduate School), Monterey, Califórnia, 2002. Disponível em: <http:// http://calhoun.nps.edu/handle/10945/4790>. Acesso em: 04 mai. 2015.

NONAKA, Ikujiro.; TAKEUCHI, Hirotaka. Criação de conhecimento na empresa. Rio de Janeiro: Campus, 1997.

NORONHA, Daisy Pires; FERREIRA, Sueli Mara Soares Pinto. Revisões de Literatura. In: CAMPELLO, Bernadete Santos; CEDÓN, Beatriz Valadares; KREMES, Jeannette Marguerite (org). Fontes de informação para pesquisadores e profissionais. Belo Horizonte: Editora UFMG, 2003.

QUINN, James Brian.; ANDERSON, Philip; FINKELSTEIN, Sydney. Gerenciando o intelecto professional: extraindo o máximo dos melhores. In: QUINN, James Brian.; ANDERSON, Philip; FINKELSTEIN, Sydney.Gestão do conhecimento. Rio de Janeiro, Campus, 2000. 
SCOTT, William Taussig.; MOLESKI, Martin X. Michael Polanyi: Scientist and Philosopher. Oxford: Oxford Scholarship Online, 2005. Disponível em: < http://www.oxfordscholarship.com/view/10.1093/019517433X.001.0001/acprof9780195174335> Acesso em: 24 mar. 2015.

SILVA FILHO, Cândido Ferreira da; SILVA, Lucas Frazão da. Da aprendizagem à Gestão do Conhecimento. In: SILVA FILHO, Cândido Ferreira da; SILVA, Lucas Frazão da. (org). Tecnologia da Informação e Gestão do Conhecimento. Campinas, SP: Editora Alínea, 2005.

STEWART, Thomas A. A riqueza do conhecimento: o capital intelectual e a organização do século XXI. Rio de Janeiro: Campus, 2002.

TARAPANOFF, Kira. Informação, conhecimento e inteligência em corporações: relações e complementaridade. In: TARAPANOFF, Kira (org.). Inteligência, Informação e conhecimento. Brasília: IBICT, 2006.

TEIXEIRA, Maria do Rocio. F. ; SOUZA, Diogo Onofre Gomes de. Fontes de informação em ciências: um estudo de uso a partir da metodologia de análise de redes sociais. In: Seminário Nacional de Bibliotecas Universitárias (SNBU), 17., 2012. Gramado, RS. Anais... Gramado, RS, 2012. Disponível em: <www.snbu2012.com.br/anais/pdf/4RFV.pdf>. Acesso em: 02 abr.2014.

TERRA, José Cláudio Cyrineu. Gestão do Conhecimento: aspectos conceituais e estudo exploratório sobre as práticas de empresas brasileiras. In: FLEURY, Maria Tereza Leme; OLIVEIRA JÚNIOR, Moacir de Miranda (org). Gestão estratégica do conhecimento: integrando aprendizagem, conhecimento e competências. São Paulo: Atlas, 2001.

TOMAÉL, Maria Inês. Redes de Conhecimento. Datagramazero: Revista de Ciência da Informação. Rio de Janeiro, v.9, n.2, 2008. Disponível em: <http://www.dgz.org.br/abr08/Art_04.htm> Acesso em: 02 abr.2014.

VALENTIM, Marta Lígia Pomim. Inteligência competitiva em organizações: dado, informação e conhecimento. Datagramazero: Revista de Ciência da Informação. Rio de Janeiro, v. 3, n. 4, 2002. Disponível em: <http://www.dgz.org.br/ago02/Art_02.htm>. Acesso em: 02 mai. 2014.

WASSERMAN, Stanley; FAUST, Katherine. Social network analysis: methods and applications. Cambridge: Cambridge University Press, 1994.

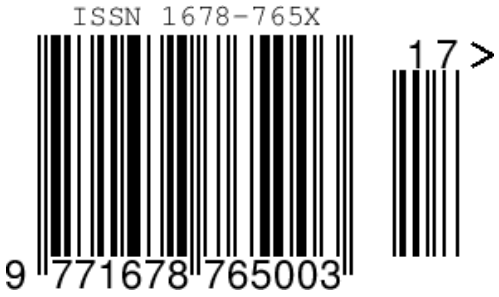


FERREIRA, Liliane Juvência Azevedo; ALVARES, Lillian Maria Araújo de Rezende; MARTINS, Dalton Lopes. $O$ conhecimento na perspectiva da construção social: as redes sociais e a gestão do conhecimento em ambientes organizacionais de bibliotecas. RDBCl: Revista Digital de Biblioteconomia e Ciência da Informação, Campinas, SP, v. 14, n. 1, p. 68-89, fev. 2016. ISSN 1678-765X. Disponível em:

$<$ http://periodicos.sbu.unicamp.br/ojs/index.php/rdbci/article/view/8640994>. Acesso em: 01 fev. 2016. doi:http://dx.doi.org/10.20396/rdbci.v14i1.8640994. 